\title{
GENERALISED ITERATION OF ENTIRE FUNCTIONS WITH FINITE ITERATED ORDER
}

\author{
DIBYENDU BANERJEE AND BISWAJIT MANDAL
}

Abstract. In this paper, considering the generalised iteration of two entire functions we investigate the growth of iterated entire functions of finite iterated order to generalise some earlier results.

Mathematics subject classification (2010): 30D35. growth.

Keywords and phrases: Entire function, generalised iteration, finite iterated order, finiteness degree,

\section{REFERENCES}

[1] D. BANERJEe AND N. Mondal, Maximum modulus and maximum term of generalized iterated entire functions, Bulletin of the Allahabad Mathematical Society, 27, 1 (2012), 117-131.

[2] L. G. BERnAL, On growth $k$-order of solutions of a complex homogeneous linear differential equations, Proc. Amer. Math. Soc., 101, 2 (1987), 317-322.

[3] W. BERGWEILER, On the growth rate of composite meromorphic functions, Complex Var., 14, (1990), $187-196$.

[4] J. Clunie, The Composition of Entire and Meromorphic Functions, Mathematical Essays Dedicated to A. J. Macintyre, Ohio University Press, 1970, 75-92.

[5] W. K. Hayman, Meromorphic Functions, Clarendon Press, Oxford, 1964.

[6] L. Kinnunen, Linear differential equations with solutions of finite iterated order, Southeast Asian Bull. Math., 22, 4 (1998), 385-405.

[7] I. LAHIRI AND D. K. ShARMA, Growth of composite entire and meromorphic functions, Indian J. Pure Appl. Math., 26, 5 (1995), 451-458.

[8] I. LAHIRI AND D. K. SHARMA, On the growth of composite entire and meromorphic functions, Indian J. Pure Appl. Math., 35, 4 (2004), 525-543.

[9] L. W. LiAO AND C. C. YANG, On the growth of composite entire functions, Yokohama Math. J., 46, (1999), 97-107.

[10] K. NiIno And N. Smita, Growth of a composite function of entire functions, Kodai Math. J., 3, (1980), 374-379.

[11] K. NIINO AND C. C. YANG, Some growth relationships on factors of two composite entire functions, in: Factorization Theory of Meromorphic Functions and Related Topics, Marcel Dekker Inc., New York/Basel, 1982, 95-99.

[12] A. P. Singh, Growth of composite entire functions, Kodai Math. J., 8, (1985), 99-102.

[13] D. SATO, On the rate of growth of entire functions of fast growth, Bull. Amer. Math. Soc., 69, (1963), 411-414.

[14] J. Tu, Z. X. Chen And X. M. Zheng, Composition of entire functions with finite iterated order, J. Math. Anal. Appl., 353, (2009), 295-304.

[15] Z. Z. ZHOU, Growth of composite entire functions, Kodai Math. J., 9, (1986), 419-420. 